\title{
Parachalastinus Galileo \& Martins (Coleoptera, Cerambycidae): espécie nova e chave para identificação
}

\author{
Carlos Eduardo de Alvarenga Julio
}

Departamento de Entomologia, Museu Nacional, Universidade Federal do Rio Janeiro. Quinta da Boa Vista, São Cristóvão, 20940-040 Rio de Janeiro, Rio de Janeiro, Brasil. Bolsista do CNPq, Processo 150583/2003-6. E-mail: ceajulio@ig.com.br

\begin{abstract}
Parachalastinus Galileo \& Martins (Coleoptera, Cerambycidae): new species and key to identification. A new species of Parachalastinus Galileo \& Martins, 2001 is described, P. flavescens sp. nov. (type locality: Panama, Chiriqui). The four species of Parachalastinus Galileo \& Martins, 2001 are keyed and illustrated. KEY WORDS. Anisocerini, Lamiinae, Neotropical, taxonomy.
\end{abstract}

RESUMO. Uma espécie nova de Parachalastinus Galileo \& Martins, 2001 é descrita, P. flavescens sp. nov. (localidadetipo: Panamá, Chiriqui). São incluídas chave de identificação e ilustração das quatro espécies.

PALAVRAS CHAVE. Anisocerini, Lamiinae, Neotropical, taxonomia.

O gênero Parachalastinus foi estabelecido por GaLILEO \& MARTins (2001:293) para Chalastinus championi Bates, 1885, designada como espécie-tipo, e Chalastinus rubrocinctus Bates, 1869, após concluírem "que as duas espécies centro-americanas não são congenéricas com as sul-americanas, principalmente pela ausência de tubérculos no mesosterno e pelo padrão de colorido". Descreveram, além disso, P. nigrescens Galileo \& Martins, 2001 do Panamá e acrescentaram chave para identificação das espécies.

O estudo de representantes do gênero, depositados na coleção do Museu Nacional/Universidade Federal do Rio de Janeiro (MNRJ) e do Museu de Zoologia/Universidade de São Paulo (MZSP), permitiu a descrição de uma espécie do Panamá (Chiriqui).

\section{Parachalastinus Galileo \& Martins, 2001}

Parachalastinus Galileo \& Martins, 2001:298.

Espécie-tipo. Chalastinus championi Bates, 1885 (designação original).

Redescrição. Fronte muito fina e esparsamente pontuada e granulada; margem inferior bissinuosa com pequeno entalhe central, nos machos e levemente bissinuosa nas fêmeas. Genas não alargadas. Olhos inteiros; lobos oculares inferiores com a metade do comprimento das genas; lobos superiores tão distantes entre si quanto, aproximadamente, 1,5 vezes a largura de um lobo. Tubérculos anteníferos projetados. Antenas ultrapassam os ápices elitrais, tanto nos machos como nas fêmeas, a dos machos, mais longas, ultrapassam por, no mínimo, quatro antenômeros e das fêmeas por apenas dois. Escapo clavado, gradualmente engrossado para o ápice, mais curto que o antenômero III; III e IV com intumescimento manifesto, provido de pêlos curtos decumbentes, no lado interno do ápice, o do IV mais discreto; V-X ligeiramente decrescentes em comprimento; antenômero XI cilíndrico, tão longo quanto ou com metade do comprimento do X.

Protórax com tubérculo lateral cônico e mais ou menos projetado; pronoto sem gibosidades ou tubérculos, com $(P$. flavescens sp. nov.) ou sem faixa longitudinal central de pubescência escamiforme colorida. Processo prosternal com cerca de $1 / 3$ da largura das cavidades procoxais, regularmente curvo, sem modificações e ligeiramente escavado no centro; processo mesosternal sem tubérculos, alargado posteriormente e com pequena reentrância no centro da margem posterior. Élitros com os lados subparalelos, terço basal do disco densa e finamente pontuado-granulado; região centro-basal com elevação granulada pouco projetada; úmeros com grânulos e ápices subarredondados. Profêmures pedunculados e clavados, o pedúnculo alcançando, aproximadamente, o meio do fêmur; protíbias sub-retas, ligeira e gradualmente expandidas para o lado externo no terço apical.

Urosternito $\mathrm{V}$ das fêmeas com, aproximadamente, o mesmo comprimento dos dois anteriores reunidos e com escavação rasa na margem centro-apical.

Discussão. Segundo Galileo \& Martins (2001: 298) Parachalastinus difere de Chalastinus Bates, 1862, entre outros caracteres, "pelo protórax unicolor", o que não é corroborado pela descrição da nova espécie.

Assemelha-se a Chalastinus, principalmente, pelo urosternito $\mathrm{V}$, das fêmeas, com o mesmo comprimento dos dois anteriores reunidos e com escavação semicircular rasa no centro da margem apical. Distingue-se pelo aspecto do escapo, 
clavado e gradualmente engrossado para o ápice; pelo antenômero III com intumescimento pronunciado e piloso no lado interno do ápice; pelo pronoto sem gibosidades; pelo processo prosternal regularmente curvo e com suave declive posterior; pelo processo mesosternal sem tubérculos; e pelo sulco précoxal, na região posterior do metasterno, não precedida por área elevada. Em Chalastinus: escapo pedunculado e clavado, abruptamente engrossado na metade apical; antenômero III com intumescimento apical discreto e desprovido de pêlos; pronoto com dois pequenos tubérculos látero-anteriores espiniformes; processo prosternal elevado entre as procoxas e com brusco declive posterior; processo mesosternal bituberculado; região posterior do metasterno com sulco pré-coxal precedido por elevação glabra.

\section{Parachalastinus flavescens sp. nov.}

\section{Fig. 1}

Etimologia. Do latim, flavus = amarelo. Alusivo à coloração da pubescência escamiforme que reveste grande parte da superfície corporal.

Macho. Tegumento castanho-escuro a preto. Pubescência escamiforme amarela, densa, forma uma larga faixa longitudinal entre os tubérculos anteníferos e prolonga-se pelo vértex, por entre os lobos oculares superiores, pelo meio do pronoto e recobre todo o escutelo; reveste a gena, os lados do protórax, o mesepisterno, o metepisterno e grande parte dos élitros; nestes uma densa pubescência branco-amarelada e castanho-escura entremeadas recobrem os tubérculos centro-basais, uma pequena área abaixo destes, os úmeros e uma larga faixa transversal pós-mediana, que não atinge a margem sutural. Todo o restante da superfície corporal revestida por pubescência decumbente branco-amarelada. Tarsômeros I-III com densos pêlos longos, decumbentes, branco-amarelados.

Fronte com pontos esparsos e pequenas rugas. Pontuação densa, grossa e profunda mais evidente na faixa amarela da cabeça e do pronoto e nas margens anterior e posterior do protórax. Antenas ultrapassam os ápices elitrais a partir do antenômero VIII; antenômeros III e IV com o mesmo comprimento, 1,3 vezes o do escapo, e intumescimento manifesto no lado interno do ápice, o do IV mais discreto; V-X ligeiramente decrescentes em comprimento; $\mathrm{X}$ com o comprimento igual ao do XI. Tubérculo lateral do protórax pouco desenvolvido, com o topo rombo. Élitros com o terço basal densamente pontuado-granulado; tubérculos centro-basais granulados e discretamente projetados. Urosternitos II-IV com a pubescência lateral mais densa.

Dimensões em milímetros. Comprimento total, 13,0; comprimento do protórax, 2,4; maior largura do protórax, 4,2; comprimento elitral, 9,5; largura umeral, 5,9.

Material-tipo. Holótipo macho, Panamá, Chiriqui: Quebrada Tisingal $(1400 \mathrm{~m}), 02 / \mathrm{V} / 1980$, Porion-Bertrand leg. (MNRJ).

Discussão. Assemelha-se a P. rubrocinctus (Bates, 1869) pelo comprimento das antenas dos machos, que ultrapassam os ápices elitrais a partir do antenômero VIII; pelo antenômero $\mathrm{XI}$, dos machos, com o mesmo comprimento que o $\mathrm{X}$ e pelo tubérculo lateral do protórax pouco desenvolvido, com o topo rombo. Distingue-se pela coloração, amarela, e distribuição da pubescência escamiforme, que recobre grande parte da superfície corporal e pela pontuação densa e profunda entre os tubérculos anteníferos, os lobos oculares superiores, no vértex, em toda a extensão longitudinal central do pronoto e nas margens anterior e posterior do protórax. Em P. rubrocinctus a superfície corporal é subglabra, com uma pubescência escura rala, exceto pela faixa transversal estreita, antes do meio dos élitros e pela mancha subarredondada, pré-apical, ambas de pubescência escamiforme vermelho-alaranjada; a pontuação é fina, discreta e bastante esparsa na cabeça e no protórax. P. flavescens sp. nov. distingue-se das demais espécies do gênero, principalmente, pelo padrão de coloração e distribuição da pubescência escamiforme e pelo comprimento das antenas e do antenômero XI em relação ao X (nos machos). Em P. championi (Bates, 1885) e $P$. nigrescens as antenas são mais longas, ultrapassando os ápices elitrais a partir do antenômero VI e o antenômero XI tem cerca de metade do comprimento do X (nos machos). Em $P$. championi a pubescência escamiforme se concentra nos élitros, numa faixa transversal pré-mediana amarelada com as bordas alaranjadas e em áreas vermelho-alaranjadas pré-apicais. Em $P$. nigrescens a superfície corporal é totalmente preta, desprovida de pubescência escamiforme colorida.

\section{Chave para as espécies de Parachalastinus}

1. Cabeça, protórax, escutelo e élitros com áreas densamente recobertas por pubescência escamiforme amarela. Panamá (Fig. 1) ........................................... P. flavescens sp. nov.

1'. Cabeça, protórax e escutelo pretos, desprovidos de áreas de pubescência escamiforme amarela; élitros totalmente pretos ou com faixa transversal pré-mediana de pubescência escamiforme vermelho-alaranjada ou amarelada e alaranjada .. 2

2. Élitros totalmente pretos. Panamá (Fig. 2) ....... P. nigrescens

2 '. Élitros com faixa transversal pré-mediana de pubescência escamiforme vermelho-alaranjada ou amarelada e alaranjada

\section{3}

3. Élitros com faixa transversal pré-mediana de pubescência escamiforme vermelho-alaranjada; antenas (machos) ultrapassam os ápices elitrais a partir do antenômero VIII; antenômero XI (machos) com o mesmo comprimento que o X. Nicarágua e Costa Rica (Fig. 3) ..................... P. rubrocinctus

3'. Élitros com faixa transversal pré-mediana de pubescência escamiforme amarelada e bordas alaranjadas; antenas (machos) ultrapassam os ápices elitrais a partir do antenômero VI; antenômero XI (machos) com a metade do comprimento do X. Costa Rica e Panamá (Fig. 4)

P. championi

Revista Brasileira de Zoologia 22 (1): 19-22, março 2005 

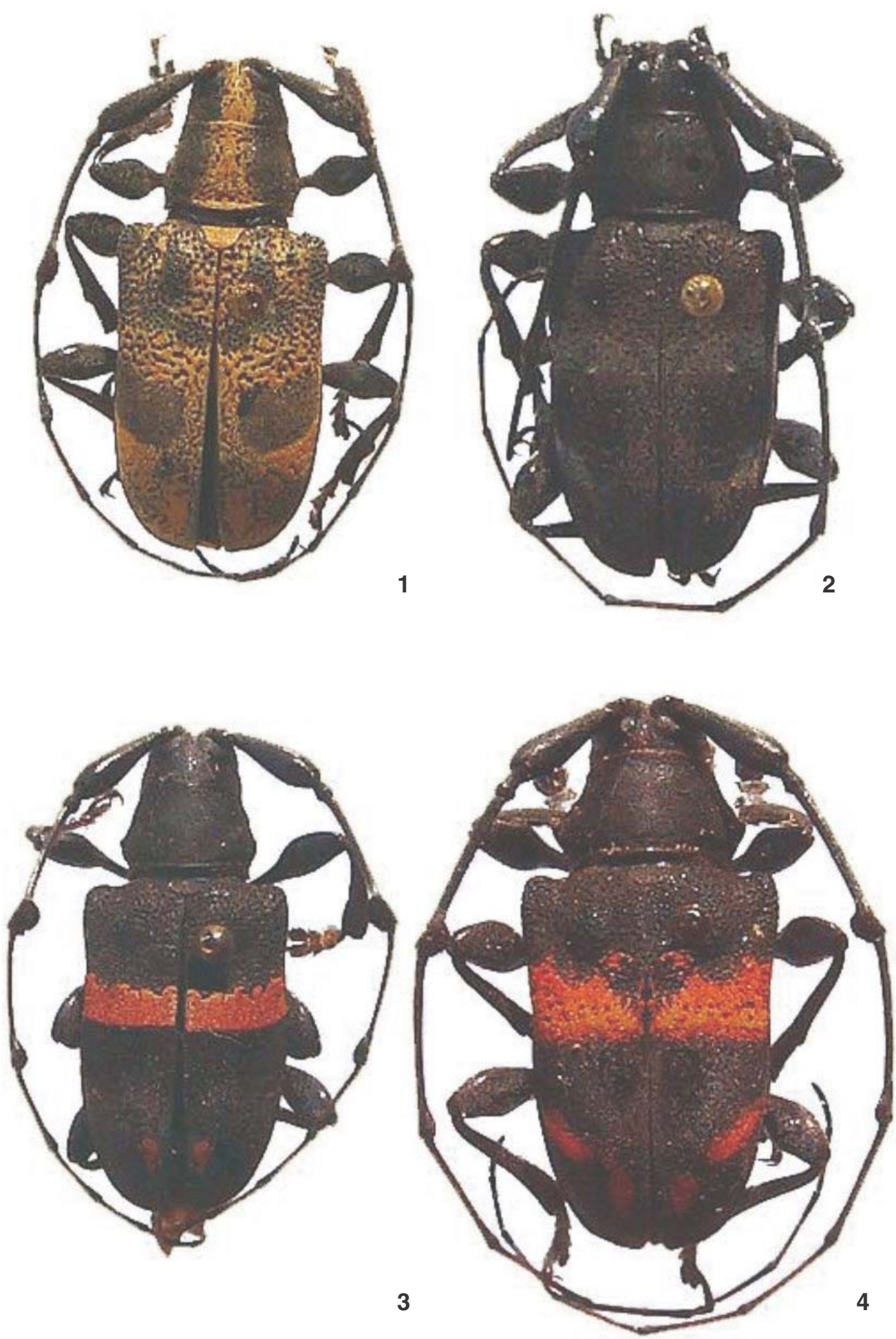

Figuras 1-4. 1. Parachalastinus flavescens sp. nov., holótipo macho (MNRJ), Quebrada Tisingal, Chiriqui, Panamá, comprimento 13,0; (2) P. nigrescens, holótipo macho (MZSP), Curundu, Panamá, comprimento 15,4; (3) P. rubrocinctus, macho (MNRJ), Zapote Upala, Alajuela, Costa Rica, comprimento 13,7; (4) P. championi, macho (MNRJ), Canal Zone, Panamá, comprimento, 16,0. 


\section{AGRADECIMENTOS}

Ao Dr. Miguel A. Monné (MNRJ) pelas sugestões e revisão do manuscrito; ao Dr. Ubirajara R. Martins (MZSP) pelo empréstimo de material; e ao Conselho Nacional de Desenvolvimento Científico e Tecnológico pela bolsa de Pós-Doutorado concedida.

\section{REFERÊNCIA BIBLIOGRÁFICA}

Galileo, M.H.M \& U.R. Martins. 2001. Revisão dos gêneros Chalastinus Bates, 1862 e Parachalastinus gen. n. (Coleoptera, Cerambycidae, Anisocerini). Giornale italiano di Entomologia, Cremona, 9: 293-303.

Recebido em 17.VI.2004; aceito em 30.XI.2004.

Revista Brasileira de Zoologia 22 (1): 19-22, março 2005 